\title{
ANALISIS KOMUNIKASI INTERPERSONAL PETUGAS LAPANGAN KELUARGA BERENCANA (PLKB) DALAM KEIKUTSERTAAN AKSEPTOR KB MEDIS OPERATIF PRIA (MOP)
}

\section{(Studi Kasus di Dusun Kumbi Desa Pakuan Kecamatan Narmada Kabupaten Lombok Barat)}

\author{
Tita Yuliastuti ${ }^{1}$, Yulanda Trisula $S Y^{2}$, Tenri Waru ${ }^{3}$ \\ ${ }^{1}$ Jurusan Ilmu komunikasi, Fakultas Ilmu Sosial dan Ilmu Politik, Universitas 45 \\ Mataram \\ ${ }^{2}$ Pascasarjana Fakultas Ilmu Sosial dan Ilmu Politik, Universitas Brawijaya \\ Malang \\ ${ }^{3}$ Pascasarjana Fakultas Ilmu Sosial dan Ilmu Politik, Universitas Tadulako \\ Sulawesi Tengah
}

\begin{abstract}
Abstrak
Masih rendahnya partisipasi pria/suami dalam $\mathrm{KB}$ dan Kesehatan Reproduksi pada dasarnya disebabkan antara lain ketidakmengertian pria akan pentingnya cara-cara berperan dalam KB dan Kesehatan Reproduksi, serta kurangnya pengetahuan dan informasi tentang macam-macam KB Pria khususnya Vasektomi atau Medis Operatif Pria (MOP). Hal ini tercermin dari adanya kebiasaan masyarakat yang masih cenderung menyerahkan sepenuhnya tanggung jawab tersebut kepada istri. Dengan keadaan ini maka Pemerintah melalui PLKB mensosialisasikan program Keluarga Berencana kepada masyarakat di setiap daerah. Metode Komunikasi Interpersonal dianggap paling efektif untuk mempengaruhi dan mengajak masyarakat untuk mengikuti KB MOP.

Tujuan penelitian ini adalah untuk Untuk mengetahui bagaimanakah komunikasi interpersonal yang dilakukan oleh Petugas Penyuluh Lapangan Keluarga Berencana (PLKB) dalam keikutsertaan akseptor KB MOP di Dusun Kumbi Desa Pakuan Kecamatan Narmada Kabupaten Lombok Barat. Penelitian ini menggunakan pendekatan kualitatif dengan metode deskriptif. Pengumpulan data dilakukan dengan teknik wawancara mendalam (In-depth interview). Wawancara mendalam dilakukan pada satu orang PLKB, lima orang yang menggunakan KB MOP dan lima orang yang tidak menggunakan KB MOP.

Kesimpulan dan hasil penelitian ini menunjukkan bahwa Komunikasi Interpersonal yang dilakukan oleh PLKB dalam keikutsertaan akseptor KB MOP di Dusun Kumbi Desa Pakuan Kecamatan Narmada adalah dengan melakukan kunjungan rumah, menggunakan bahasa yang mudah dipahami, menggunakan media berupa brosur atau leaflet, dan melakukan pendekatan dengan tokoh masyarakat setempat.
\end{abstract}

Kata Kunci : Komunikasi Interpersonal, PLKB, KB MOP 


\begin{abstract}
The low participation of man/husbands in Family Planning and Reproductive Health is basically caused by men's lack of understanding on the importance of ways to play a role in Family Planning and Reproductive Health, as well as the lack of knowledge and information on KB types of Men especially Vasectomy or Male Operative Medical (MOP). This is reflected in the habit of the people who still tend to surrender the responsibility to the wife. With this situation the Government through PLKB socialize Family Planning program to the community in every region. Interpersonal Communication Method is considered the most effective to influence and invite the community to follow KB MOP.

The purpose of this research is to know how the interpersonal communication done by Family Planning Extension Officer (PLKB) in the participation of KB MOP acceptors in Kumbi Hamlet of Pakuan Village, Narmada District, West Lombok regency. This research uses qualitative approach with descriptive method. Data collection is done by in-depth interview technique. In-depth interviews were conducted on one PLKB man, five people using KB $M O P$ and five people who did not use KB MOP.

The conclusions and results of this study indicate that the Interpersonal Communication conducted by PLKB in the participation of KB MOP acceptors in Kumbi Hamlet of Pakuan Village, Narmada District is by making home visits, using understandable language, using brochure or leaflet media, and approaching community leaders local.
\end{abstract}

Keywords: Interpersonal Communication, PLKB, KB MOP 


\section{PENDAHULUAN}

Penduduk sebagai modal dasar dan faktor dominan pembangunan harus menjadi titik sentral dalam pembangunan berkelanjutan, karena di samping sebagai pelaksana pembangunan, penduduk juga merupakan sasaran akhir dari perencanaan pembangunan seperti kesejahteraan penduduk, kesehatan penduduk, keamanan penduduk, kualitas sumber daya manusia dan sebagainya. Jumlah penduduk yang besar dengan kualitas rendah dan pertumbuhan yang cepat akan memperlambat tercapainya pembangunan yang ideal.

International Conference on Population and Development (ICPD) 1994 telah menyepakati perubahan paradigma baru program KB secara global, yaitu dari konsep dan pelaksanaan program pengendalian populasi dan penurunan fertilitas menjadi lebih kearah pendekatan kesehatan reproduksi yang lebih memperhatikan hak-hak reproduksi. Dengan konsep baru tersebut, penanganan kesehatan reproduksi menjadi lebih luas yang antara lain meliputi pemenuhan kebutuhan kesehatan reproduksi setiap individu, baik pria maupun perempuan sepanjang siklus hidupnya, termasuk hak-hak reproduksi perempuan, kesetaraan dan keadilan gender, dan masalah tanggung jawab pria dalam kaitan dengan kesehatan reproduksi keluarganya menuju terwujudnya keluarga berkualitas (BKKBN, 2010:31).

Rendahnya partisipasi pria/suami dalam KB dan Kesehatan Reproduksi pada dasarnya disebabkan antara lain ketidakmengertian pria akan pentingnya cara-cara berperan dalam KB dan Kesehatan Reproduksi, serta kurangnya pengetahuan dan informasi tentang macam-macam KB Pria. Hal ini tercermin dari adanya kebiasaan masyarakat yang masih cenderung menyerahkan sepenuhnya tanggung jawab tersebut kepada istri. Padahal sebenarnya masalah KB adalah tanggung jawab suami istri.

Program peningkatan partisipasi pria dalam ber-KB telah dilaksanakan selama beberapa tahun, namun penggunaan metode kontrasepsi pria masih rendah. Menurut Data SDKI 2012 yang melaporkan penggunaan kondom dan senggama terputus, masing-masing hanya $2 \%$ dan 1 $\%$ menggunakan pantang berkala. Sedangkan untuk MOP masih kurang dari $1 \%(0,3 \%)$.

Berbagai upaya promosi tentang KB Pria perlu dikembangkan, sehingga para pria dan istrinya akan lebih memahami akan hal-hal yang berkaitan dengan KB Pria khususnya MOP, baik cara kerja, kelebihan, keterbatasan maupun tempat dimana pelayanan KB MOP dapat 
diperoleh. Keberhasilan yang akan dicapai pemerintah dalam Program Keluarga Berencana terutama KB MOP ini tidak dapat dilepaskan dari adanya peranan Petugas Lapangan Keluarga Berencana (PLKB).

Petugas Lapangan Keluarga Berencana (PLKB) merupakan ujung tombak pengelola program KB di lini lapangan. Penyuluh KB juga merupakan salah satu komponen penting dalam upaya peningkatan perekonomian dan kesejahteraan masyarakat, juga sebagai indikator kemajuan yang telah dicapai suatu daerah. Penyuluh KB bersentuhan langsung dengan masyarakat dalam memberikan berbagai penyuluhan program KB.

Komunikasi dinilai sebagai aspek yang penting ketika melakukan penyuluhan. Penyuluh Keluarga Berencana dalam mempromosikan program KB pada pasangan usia subur khususnya MOP biasanya melakukan pendekatan-pendekatan terlebih dahulu seperti sosialisasi atau penyuluhan, konseling baru kemudian melakukan kunjungan ke rumah masyarakat (door to door) dan menggunakan komunikasi interpersonal. Komunikasi Interpersonal dipilih oleh PLKB karena dalam wawancara biasanya ada yang dibicarakan secara detail dan pribadi serta calon akseptor masih malu dan sungkan untuk bertanya. Sehingga dengan komunikasi interpersonal, PLKB dapat langsung berkomunikasi tentang masalah atau hal-hal yang dihadapi calon akseptor dan dapat memberikan jalan keluar serta langsung tahu respon balik dari orang tersebut.

Hal ini sesuai dengan beberapa tujuan Komunikasi Interpersonal menurut Muhammad, Arni (2009), yaitu (1) Merubah sikap dan tingkah laku, dan (2) untuk membantu. Dimana komunikasi ini berupa proses dua arah dimana informasi, pemikiran, ide, perasaan atau opini disampaikan atau dibagikan melalui kata-kata, tindakan maupun isyarat untuk mencapai pemahaman bersama. Komunikasi yang baik berarti bahwa para pihak terlibat secara aktif yaitu antara Penyuluh Keluarga Berencana dan Masyarakat. Hal ini akan menolong mereka untuk mengalami cara baru mengerjakan atau memikirkan sesuatu, dan hal ini kadang-kadang disebut pembelajaran partisipatif. Semua aktifitas manusia melibatkan komunikasi, namun karena kita sering menerimanya begitu saja, kita tidak selalu memikirkan bagaimana kita berkomunikasi dengan yang lain dan apakah efektif atau tidak.

Komunikasi yang dilakukan PLKB terhadap masyarakat ini dapat disebut pula sebagai promosi kesehatan. Hal ini disebabkan oleh PLKB yang melakukan tugasnya dengan 
mempengaruhi, dan atau mengajak orang lain, baik individu, kelompok, atau masyarakat, agar melaksanakan perilaku hidup sehat melalui program KB.

Program kependudukan dan KB Provinsi Nusa Tenggara Barat pada bulan JanuariDesember tahun 2016 mencatat bahwa untuk peserta aktif KB wanita yang meliputi KB Intra Uterine Devices (IUD), Medis Operatif Wanita (MOW), Implant, Suntik dan Pil total targetnya 792.183, realisasinya 799.120 (100,88\%). Peserta aktif KB pria yang menggunakan Kondom $14.499(90,34 \%)$ sedangkan peserta KB aktif MOP 4.370 (95,75\%). Hal ini menggambarkan bahwa pelaksanaan Program KB di Provinsi NTB pada umumnya sudah berhasil. Namun untuk realisasi Pencapaian khususnya Peserta KB Baru Pria MOP masih rendah yaitu terlihat dari data bulan Januari sampai dengan Desember 2016 hanya 263 atau 0,19\% dari sasaran kinerja sebanyak 136.030 (Data F1,F2 BKKBN NTB, 2016).

Begitu pula dengan salah satu dari sepuluh Kabupaten/Kota yang ada di Provinsi Nusa Tenggara Barat yaitu Kabupaten Lombok Barat yang juga berupaya untuk meningkatkan pencapaian kesertaan KB Pria terutama MOP. Pada tahun 2016 Peserta KB Aktif MOP tercatat sebanyak $244(0,21 \%)$ dari 147.374 PUS. Sedangkan pada tahun 2016 untuk Peserta KB Baru Pria yang menggunakan MOP hanya 23 atau 0,14\% dari sasaran kinerja sebanyak 16.520 (Data F1, F2 BKKBN NTB, 2016). Laporan Statistik Rutin BKKBN Provinsi Nusa Tenggara Barat sampai dengan bulan Desember 2016 juga menunjukkan bahwa satu Kecamatan dari 10 Kecamatan yang ada di Kabupaten ini, yakni Kecamatan Narmada tepatnya di Dusun Kumbi Desa Pakuan melaporkan ada 11 orang yang menggunakan KB MOP.

Sekalipun jumlah peminat KB MOP di Dusun Kumbi Desa Pakuan relatif sedikit dibandingkan dengan jumlah pemakai KB yang lain, namun merupakan jumlah yang paling banyak jika dibandingkan dengan 5 Dusun lain yang ada di Desa Pakuan Kecamatan Narmada. Seperti di Dusun Lembah Sepage hanya 2 orang, Jurang Mekar 1 orang, Jurang Malang 1 orang dan Dusun Pesantek 2 orang (Data dari hasil wawancara dengan H. Mursidi (PLKB) tanggal 15 Mei 2017).

Dari beberapa uraian diatas, menurut Joseph A.Devito (1986) dalam BKKBN (2006) agar Komunikasi Interpersonal dapat berjalan secara efektif, maka ada beberapa hal yang perlu diterapkan oleh seorang PLKB yaitu diantaranya keterbukaan (openness), empati (empathy), sikap mendukung (supportiveness), sikap positif (positiveness), dan kesetaraan (equality). 
Untuk itu tujuan dari penelitian ini adalah untuk meneliti bagaimana komunikasi Interpersonal yang dilakukan oleh Petugas penyuluh Lapangan Keluarga Berencana dalam keikutsertaan akseptor KB MOP di Dusun Kumbi Desa Pakuan Kecamatan Narmada Kabupaten Lombok Barat.

\section{METODE PENELITIAN}

Didalam penelitian ini, pendekatan yang digunakan adalah pendekatan kualitatif. Sedangkan tipe penelitian ini menggunakan tipe deskripsi kualitatif, dimana peneliti mendiskripsikan atau mengkonstruksi wawancara-wawancara mendalam terhadap subjek penelitian. Penelitian kualitatif adalah penelitian yang bertujuan untuk menjelaskan suatu fenomena sedalam-dalamnya melalui pengumpulan data yang sedalam-dalamnya, dengan demikian tidak terlalu mengutamakan besarnya populasi atau sampling (Kriyantono, 2008).

\section{Metode Pengumpulan Data}

Peneliti menggunakan beberapa teknik dalam mengumpulkan data-data yang diperlukan dalam penelitian ini, antara lain :

a. Teknik observasi yaitu kegiatan mengamati secara langsung pada objek penelitian (Kriyantono, 2008).

Dalam menggunakan teknik observasi ini peneliti bisa mengamati perilaku non verbal maupun perilaku verbal dari PLKB, yaitu cara berkomunikasi yang dilakukan, mimik muka dan sikap PLKB saat melakukan interaksi dengan orang lain.

b. Wawancara mendalam yaitu suatu cara mengumpulkan data atau informasi dengan cara langsung bertatap muka dengan PLKB, lima (5) orang akseptor MOP dan lima (5) orang yang bukan akseptor KB MOP agar mendapatkan data yang lengkap dan mendalam (Kriyantono, 2008).

Sebelum melakukan wawancara, peneliti meminta ijin kepada informan untuk melakukan wawancara dengan cara memperkenalkan diri dan menyerahkan formulir lembar persetujuan sebagai partisipan/responden dalam penelitian ini. Kemudian pada saat melakukan wawancara, peneliti merekam pembicaraan dan dituangkan dalam bentuk transkip wawancara. 
c. Dokumentasi yaitu pengumpulan data yang dilakukan pada berbagai dokumen baik yang bersifat pribadi maupun umum antara lain terdiri dari berbagai bentuk catatan tertulis, studi kepustakaan dan sampai kepada berbagai sumber resmi dokumen pemerintah (H.L. Fathurrahman, 2016)

Dari hasil penelitian, peneliti hanya mendapatkan data berupa foto, dokumen pemerintah, dan catatan tertulis.

\section{Tehnik Analisis Data}

Adapun dalam teknik analisa data, peneliti mengacu pada model Interaktif oleh Miles dan Huberman yaitu sebagai berikut :

1. Pengumpulan data

Pengumpulan data adalah data pertama atau mentah dikumpulkan dalam suatu penelitian. Data mentah berupa wawancara dengan PLKB, lima (5) orang akseptor MOP dan lima (5) orang yang bukan akseptor MOP, hasil observasi tentang kegiatan PLKB, percakapan yang dilakukan, serta dokumen berupa laporan bulanan PLKB

2. Reduksi data atau penyederhanaan data

Reduksi data dapat diartikan sebagai proses pemilihan pemutusan perhatian pada penyederhanaan, pengabstrakan, dan transformasi data kasar yang muncul dari catatan tertulis data yang menajamkan, menggolongkan, mengarahkan membuang yang tidak perlu dan mengorganisasikan data sedemikian rupa sehingga kesimpulan dapat ditarik dan diverivikasi.

Berdasarkan temuan dilapangan peneliti telah menggolongkan data-data yang ditampilkan pada hasil wawancara dan observasi.

3. Penyajian data

Penyajian data merupakan alur penting yang kedua dari kegiatan analisis penelitian membatasi suatu "penyajian" sebagai suatu kumpulan informasi tersusun yang memberikan kemungkinan adanya penarikan kesimpulan atau pengambilan tindakan. Peneliti menyajikan data dalam bentuk narasi yang disusun berdasarkan informasi yang sudah diseleksi yang berguna untuk penelitian. Penggunaan bagan dan tabel hanya dilakukan untuk bagian-bagian tertentu yang dimaksudkan untuk semakin memperjelas gambaran data dan hasil penelitian.

4. Penarikan Kesimpulan dan Verifikasi

Menarik kesimpulan data ini disusun pada waktu penelitian mendapatkan inti data yang diperlukan dalam penelitian, setelah pengumpulan data berakhir, peneliti berusaha menarik 
kesimpulan atau vertivikasi berdasarkan fielnote. Apabila filenote dirasa cukup atau tidak didapatkan peneliti wajib mencari kelengkapan dari data di lapangan secara khusus sebagai catatan-catatan (Sugiyono, 2008).

Setelah mendapatkan data-data yang dibutuhkan, peneliti akhirnya menarik kesimpulan.

\section{HASIL DAN PEMBAHASAN}

KB MOP adalah salah satu metode kontrasepsi untuk pria selain kondom, dimana masih banyak masyarakat yang belum tahu tentang KB jenis ini. PLKB sebagai ujung tombak dalam program keluarga berencana mempunyai tugas yaitu untuk mensosialisasikan dan mengajak masyarakat untuk mengikuti KB MOP dengan tujuan untuk mensukseskan program pemerintah yaitu mencegah bahaya ledakan penduduk. Dalam pelaksanaannya, PLKB Dusun Kumbi melakukan beberapa cara dalam mengenalkan KB MOP ini kepada masyarakat yaitu dengan melakukan penyuluhan umum dan penyuluhan secara personal. Penyuluhan secara umum dirasa kurang efektif dalam mengajak masyarakat untuk mengikuti KB MOP. Oleh karena itu PLKB melakukan penyuluhan secara interpersonal. Hal ini tidaklah mudah, dikarenakan beberapa masyarakat masih mempunyai pendapat bahwa istri atau wanitalah yang seharusnya menggunakan KB. Sehingga PLKB harus bekerja keras untuk mempromosikan KB MOP ini.

Guna untuk mensukseskan program pemerintah tersebut, PLKB Dusun Kumbi melakukan komunikasi interpersonal yang bertujuan untuk mengajak dan mempengaruhi masyarakat khususnya bapak-bapak atau laki-laki yang sudah menikah dan mempunyai anak dua atau sudah lebih dari dua untuk mengikuti KB MOP. Kegiatan ini sesuai dengan tujuan komunikasi interpersonal yaitu untuk merubah sikap dan tingkah laku serta membantu orang lain. Dengan kata lain, PLKB melakukan komunikasi interpersonal untuk mengubah masyarakat yang awalnya belum mengikuti KB MOP setelah diberi penjelasan akhirnya mau ikut KB MOP dan membantu masyarakat, terutama yang ekonominya lemah, anaknya sudah banyak dan istri tidak cocok untuk menggunakan KB maka suamilah yang berperan untuk ikut KB MOP.

Komunikasi interpersonal yang dilakukan PLKB dengan cara mendatangi rumah calon akseptor dan melakukan penyuluhan secara pribadi. Hal ini dilakukan karena akseptor ada yang kurang mampu berkomunikasi di depan umum atau malu dan meminta penjelasan yang lebih detail. Komunikasi interpersonal memberikan ruang bagi PLKB untuk dapat menjelaskan informasi secara lebih dekat dan lebih rinci serta terbuka terkait dengan KB MOP. Sehingga, 
informasi yang diterima oleh akseptor lebih tepat sasaran, karena hal ini merupakan hal yang sensitif sehingga menjadikan komunikasi dengan tatap muka langsung membuat akseptor lebih nyaman dalam berkomunikasi.

PLKB sebagai seorang komunikator melakukan komunikasi interpersonal dengan tatap muka langsung dengan calon akseptor atau dengan kata lain dengan cara bertemu langsung dan berhadap-hadapan akan membawa suasana lebih cair dan akrab sehingga emosi yang ada dalam diri seseorang atau komunikan akan lebih mudah untuk diketahui, hal ini akan memudahkan pemberi informasi untuk mengetahui maksud dan tujuan dari penerima informasi secara langsung. Selain itu, dengan melakukan komunikasi interpersonal, umpan balik akan lebih cepat terjadi dan mengurangi terjadinya bias-bias pada informasi sehingga tujuan atau isi dari pesan tersebut dapat lebih mudah dipahami oleh penerima informasi.

Komunikasi interpersonal dianggap sangat potensial sebagai cara membujuk atau mempengaruhi orang lain, karena pada saat penyampaian pesan dapat menggunakan kelima indera untuk mempertinggi daya bujuk pesan yang dikomunikasikan pada komunikan. Sebagai komunikasi yang paling lengkap dan paling sempurna, Komunikasi antarpribadi sangat berperan penting selama manusia masih mempunyai emosi. Kenyataannya komunikasi tatap muka ini membuat suasana lebih nyaman dan akrab dengan orang lain. Berbeda jika komunikasi dilakukan lewat media massa atau penyuluhan umum. Hal ini sesuai dengan ciri-ciri tetap komunikasi interpersonal yang menyatakan bahwa komunikasi interpersonal saling mengubah, dimana ketika diskusi dilakukan oleh dua orang yang bertemu secara langsung akan membuat komunikan menjadi berubah sikap, cara pandang dan cara berfikirnya bahkan cara untuk berperilaku.

PLKB Dusun Kumbi dalam melakukan komunikasi interpersonal untuk mengajak calon akseptor mengikuti KB MOP, menggunakan tehnik komunikasi persuasif. Dimana tugas seorang PLKB disini adalah untuk mempengaruhi, membujuk dan mengajak orang lain untuk merubah sikap, pendapat dan perilaku dari yang sebelumnya tidak atau belum mengikuti KB MOP agar mengikuti KB MOP.

Seorang PLKB dalam melakukan komunikasi interpersonal juga perlu memperhatikan sikapnya. Karena setiap sikap yang ditampilkan merupakan pesan nonverbal yang akan menegaskan pesan verbal yang disampaikan. Sikap yang sudah dilakukan oleh PLKB Dusun Kumbi saat berhadapan dengan masyarakat calon akseptor yaitu menampilkan sikap yang ramah, sopan, empati 
dan terbuka. Selain itu sebagai seorang PLKB hendaknya mempunyai kredibilitas yang baik dihadapan komunikan dalam setiap melakukan komunikasi. Karena dengan memiliki kredibilitas yang baik sebagai seorang komunikator KB, maka akan lebih mudah untuk mempengaruhi dan meyakinkan komunikan untuk mengikuti program KB MOP. Hal ini sejalan dengan apa yang sudah dilaksanakan PLKB Dusun Kumbi yaitu memberikan penjelasan tentang KB MOP dengan bahasa yang mudah dimengerti, mudah dipahami dan tidak ditutup-tutupi sehingga menimbulkan kepercayaan masyarakat kepada PLKB.

Tidak dapat dipungkiri, bahwa keikutsertaan akseptor KB di Dusun Kumbi dikarenakan karena PLKB dalam menyampaikan pesan menggunakan komunikasi interpersonal dengan teknik persuasif. Pada kenyataannya saat dilakukan penyuluhan secara umum, masih banyak warga yang malu bertanya karena menganggap masalah yang berhubungan dengan KB khususnya KB MOP ini merupakan masalah pribadi, apalagi yang memakai KB ini adalah seorang laki-laki. Maka komunikassi interpersonal ini sangat efektif untuk mempengaruhi seseorang.

Keefektivitasan komunikasi interpersonal berjalan dengan baik pada saat PLKB menginformasikan KB MOP di dusun Kumbi ini. Pertama yaitu keterbukaan (Openness), PLKB sangat terbuka dengan masyarakat dimana PLKB Dusun Kumbi sebagai komunikator memberikan penjelasan tentang KB MOP kepada calon akseptor tanpa ditutup-tutupi bahwa jika sudah ikut KB MOP maka akseptor tidak akan bisa menghamili istrinya lagi. Kedua, PLKB juga bersikap empati (empathy) yaitu kemampuan seseorang untuk merasakan kalau seandainya menjadi orang lain, dapat memahami sesuatu yang dialami oleh orang lain. Apalagi disini PLKB dan akseptor adalah sesama lelaki. PLKB dalam hal ini mengungkapkan secara non verbal yaitu melalui ekspresi wajah dengan bersikap baik, ramah dan sopan serta menggunakan bahasa yang mudah dimengerti ketika melakukan komunikasi interpersonal dengan akseptor. Ketiga, sikap mendukung (supportiveness) artinya masing-masing pihak yang berkomunikasi memiliki komitmen untuk mendukung terselenggaranya interaksi secara terbuka. Disini PLKB dalam melakukan komunikasi interpersonal dirumah calon akseptor, PLKB sebisa mungkin mengajak istri dari calon akseptor untuk ikut diberi penjelasan. Hal ini agar istri ikut mendukung suami untuk ikut KB MOP. Keempat, sikap positif dimana PLKB menanamkan rasa percaya kepada akseptor. Sehingga calon akseptor percaya bahwa KB MOP ini berguna untuk kesehatan dan kesejahteraan keluarga sehingga akhirnya mau untuk ikut KB MOP. Kelima, Kesetaraan 
(equality) artinya pengakuan bahwa kedua belah pihak memiliki kepentingan yang sama dan saling memerlukan.

Di sisi lain, keikutsertaan akseptor KB MOP juga dikarenakan PLKB memilih waktu yang tepat untuk dapat melakukan kunjungan rumah dalam rangka melakukan komunikasi interpersonal agar masyarakat Dusun Kumbi mau ikut KB MOP yaitu berada pada waktu siang hingga malam hari, hal ini dikarenakan pada pagi harinya masyarakat bekerja. Tentunya, apabila kunjungan rumah dilakukan pada siang atau bahkan malam hari akan menjadi lebih efektif dan efisien karena waktu tersebut merupakan waktu luang masyarakat untuk dapat menerima informasi secara jelas dengan tatap muka secara langsung.

Keikutsertaan masyarakat Dusun Kumbi untuk mengikuti KB MOP, juga dipengaruhi oleh beberapa faktor. Salah satunya yaitu cara penyampaian pesan yang dilakukan oleh PLKB. Dalam hal untuk mempermudah menjelaskan ke masyarakat tentang KB MOP, PLKB dalam melakukan komunikasi interpersonal dibantu dengan menggunakan media salah satunya yaitu brosur. Hal ini sejalan dengan apa yang dnyatakan oleh Effendy (2015) bahwa penyampaian pesan yang sifatnya persuasif atau mengajak, dengan menggunakan komunikasi tatap muka akan lebih efektif dan efisien jika ditambah dengan beberapa alat bantu seperti leaflet, brosur dan sebagainya, karena kerangka acuan komunikan dapat diketahui dengan jelas oleh komunikator dan karena prosesnya langsung seketika maka umpan balikpun berlangsung seketika sehingga komunikator dapat dengan cepat mengetahui respon dari komunikan akan suatu informasi yang diberikannya tersebut.

Intensitas PLKB dalam melakukan komunikasi interpersonal juga tidak hanya sekali melakukan kunjungan rumah. Dalam pelaksanaannya PLKB melakukan komunikasi tatap muka sampai dua atau tiga kali guna meyakinkan calon akseptor. Dari menjelaskan tentang KB MOP, meyakinkan calon akseptor agar tidak ragu lagi sampai dengan penandatanganan inform consent. Karena PLKB sebagai seorang komunikator harus mampu untuk mengetahui dan menganalisis keadaan sasaran komunikan yang akan ditujunya, Keberhasilan dari penyampaian suatu informasi, terlebih informasi yang bersifat persuasi atau mengajak kepada sesuatu harus memperhatikan faktor-faktor psikologis dari komunikannya. Sebagaimana yang dijelaskan oleh Mulyana (2007) bahwa mengetahui faktor psikologis menjadi sangat penting terhadap berhasil atau tidaknya seorang komunikator dalam mempengaruhi cara pandang, cara berpikir dan bahkan perilaku dari seseorang akan sangat ditentukan oleh faktor psikologis tersebut. Komunikasi yang 
menekankan pada terjalinnya dan terbangunnya hubungan antar pribadi dapat membantu komunikator untuk dapat mencari dan mengetahui kondisi dari psikologis seseorang.

Proses komunikasi interpersonal yang dilakukan PLKB KB MOP merupakan salah satu proses dalam mengajak masyarakat atau mempersuasi masyarakat untuk ikut dalam menggunakan KB MOP untuk itu dalam proses persuasif, pesan-pesan komunikasi akan efektif apabila memiliki kemampuan mengubah secara psikologis minat atau perhatian individu dengan cara sedemikian rupa, sehingga individu akan menanggapi pesan-pesan komunikasi sesuai dengan kehendak komunikator. Dengan perkataan lain, kunci keberhasilan persuasi terletak pada kemampuan mengubah struktur psikologis internal individu sehingga hubungan psikomotorik antara proses internal yang laten (motivasi, sikap dan lain-lain) dengan perilaku yang diwujudkan sesuai dengan kehendak komunikator.

PLKB sebagai seorang komunikator, dalam pelaksanaannya untuk mengajak dan mempengaruhi masyarakat agar ikut KB MOP juga melakukan pendekatan dengan tokoh masyarakat seperti Kepala Dusun Kumbi. Dengan menjadikannya sebagai seorang motivator dan penghubung untuk membantu mempromosikan KB MOP kepada masyarakat. Terlebih lagi Kepala Dusun Kumbi sudah terlebih dahulu ikut KB MOP sehingga bisa membagikan pengalaman dan manfaat dari KB MOP. Hal ini sangat efektif untuk meningkatkan kepercayaan dan kesadaran masyarakat sehingga bersedia menggunakan dan tertarik mengikuti KB MOP.

Realitas yang ditemukan pada warga Dusun Kumbi Desa Pakuan Kecamatan Narmada Kabupaten Lombok Barat telah mengerti dan mulai memahami pentingnya mengikuti KB MOP tersebut, walaupun belum semua warga bersedia mengikuti dikarenakan istri yang belum menyetujui, masih takut untuk melakukan KB MOP serta anggapan bahwa istri sudah ikut KB jadi suami tidak perlu ber KB. Untuk itu promosi kesehatan masih harus terus dilakukan oleh PLKB.

Promosi kesehatan/pendidikan kesehatan merupakan cabang dari ilmu kesehatan yang bergerak bukan hanya dalam proses penyadaran masyarakat atau pemberian dan peningkatan pengetahuan masyarakat tentang kesehatan semata, akan tetapi di dalamnya terdapat usaha untuk memfasilitasi dalam rangka perubahan perilaku masyarakat. Sehingga, penguatan dan peningkatan kembali pada aspek pengetahuan masyarakat perlu dilakukan oleh PLKB dan tokohtokoh yang berpengaruh di masyarakat. Terutama peran dari seorang Petugas Lapangan Keluarga Berencana (PLKB) perlu meningkatkan kembali praktek komunikasi interpersonal seperti 
meningkatkan kembali kemampuan berkomunikasi, kemampuan bekerja dengan data dan kemampuan membangun jaringan dan koordinasi dengan berbagai pihak. Di samping itu, pembentukan grup pelopor, sangat diperlukan di Dusun Kumbi hal ini untuk dapat merangsang warga yang belum bersedia mengikuti program KB MOP akan berubah pikiran untuk bersedia mengikuti program KB MOP tersebut. Pembentukan grup pelopor ini merupakan suatu kegiatan menyeleksi dan memotivasi keluarga agar menjadi teladan atau kader dan berperan aktif dalam pengelolaan Program KB Nasional. Pembentukan grup pelopor diperlukan bagi warga dusun Kumbi untuk memberikan penguatan dan keyakinan yang lebih agar masyarakat atau warga yang belum bersedia menggunakan KB MOP berubah menjadi yakin dan bersedia menggunakan KB MOP tersebut.

Sehingga dengan melihat cermin dari masyarakat atau warga yang lain, yang telah mengikuti program KB MOP tersebut diharapkan akan mengubah cara pandang, cara berpikir dan bahkan cara berperilaku. Hal ini sesuai dengan ciri dari komunikasi interpersonal itu sendiri adalah untuk mengubah perilaku atau saling mengubah, karena KB MOP ini merupakan informasi yang mengandung ajakan-ajakan atau bersifat persuasif sehingga peningkatan kembali komunikasi-komunikasi interpersonal perlu dilakukan oleh PLKB dan tokoh masyarakat.

\section{KESIMPULAN}

Komunikasi Interpersonal yang dilakukan oleh PLKB dalam keikutsertaan akseptor KB MOP di Dusun Kumbi dilakukan secara tatap muka ke masing-masing rumah akseptor. Media yang digunakan untuk membantu menjelaskan atau mempromosikan KB MOP menggunakan brosur atau leaflet. PLKB dalam rangka melakukan komunikasi interpersonal untuk menjelaskan tentang KB MOP juga melakukan pendekatan kepada masyarakat dengan mendekati orang yang berpengaruh di desa tersebut. Alasan warga dusun Kumbi yang bersedia mengikuti KB MOP dikarenakan beberapa hal yakni dipengaruhi oleh kondisi istri, pertimbangan anak yang sudah semakin banyak dan alasan ekonomi. Sedangkan yang belum bersedia menggunakan atau mengikuti KB MOP dikarenakan mereka masih muda, masih ingin memiliki anak kembali, masih takut dan para istri mereka belum setuju apabila suaminya mengikuti program KB MOP serta adanya anggapan bahwa istri sudah menggunakan KB yang lain sehingga suami tidak perlu ber KB lagi.

\section{UCAPAN TERIMA KASIH}


Penulis mengucapkan terima kasih kepada beberapa pihak yang telah membantu penulis dalam menyempurnakan jurnal ini. Adapun ucapan terima kasih ini ditujukan kepada :

1. Bapak Yulanda Trisula SY, S.I.Kom., M.I.Kom selaku Ketua Program Studi Ilmu Komunikasi sekaligus Dosen Pembimbing I

2. Ibu Tenri Waru, S.Sos., M.I.Kom selaku Dosen Pembimbing II.

3. H. Mertiadi, S.Sos selaku Pengawas UPT KB Kecamatan Narmada atas bantuan dan bimbingannya.

4. H. Mursidi, S.H selaku Penyuluh Keluarga Berencana Dusun Kumbi Desa Pakuan kecamatan Narmada atas partisipasi dan dukungannya.

\section{DAFTAR PUSTAKA}

BKKBN. 2006. Pedoman Teknis Komunikasi Interpersonal/Konseling bagi Penyuluh KB, Jakarta.

BKKBN. 2010. Direktorat Peningkatan Partisipasi Pria. Peningkatan Partisipasi Pria.

Effendy, Onong Uchjana. 2015. Ilmu Komunikasi (teori dan Praktek). PT. Remaja Rosdakarya, Bandung.

Fathurrahman, Lalu. 2016. Pengantar Metodologi Penelitian Ilmu Sosial/Ilmu Komunikasi. Fakultas Ilmu Sosial dan ilmu Politik Universitas 45 Mataram.

Kriyantono, Rachmat. 2008. Teknis Praktis Riset Komunikasi. Kencana Prenada Media Group, Jakarta.

Muhammad, Arni. 2009. Komunikasi Organisasi.Bima Aksara, Jakarta.

Sugiyono. 2008. Metodelogi penelitian Kuantitatif, Kualitatif, dan R\&D. Alfabeta, Bandung. 